\title{
ANÁLISE DE CONFLITO DE CRENÇAS SOBRE O APRENDIZADO DE LÍNGUAS ESTRANGEIRAS: O ALUNO ADULTO NA CRISE DO NÍVEL INTERMEDIÁRIO
}

\author{
Regina Célia Halu ${ }^{1}$ \\ Jeanne Marie Paraná2
}

\begin{abstract}
RESUMO
No nível intermediário, professores e alunos freqüentemente percebem que o processo de aprendizagem de uma língua estrangeira atingiu um ponto crítico. Os alunos tendem a apresentar um grau crescente de ansiedade à medida que sentem que não estão mais progredindo ou progridem muito vagarosamente. Alguns desistem. Outros recorrem a seus professores, os quais sentem-se muitas vezes responsáveis pela situação. Freqüentemente, contudo, acabam recorrendo a técnicas e atividades que não são suficientemente eficazes. Nem alunos, nem professores conseguem entender o cerne do problema. O nível intermediário é um ponto chave no processo de aprendizagem, no qual os alunos mais precisam refletir e agir com responsabilidade e autonomia quanto ao seu próprio aprendizado. É também o momento em que os professores precisam ajudá-los a continuar desenvolvendo esta independência e se tornar mais conscientes de como se dá a aprendizagem de uma outra língua. Ocorre que, devido a uma cultura de aprender e ensinar fortemente centrada no professor, que tende a atuar de maneira coerente com uma tradição paternalista na sociedade brasileira, muitas vezes nem o aluno aprendeu como exercer sua autonomia, nem o professor sabe como promover um aprendizado em que, ambos, professor e aluno, sejam sujeitos engajados no aprender. A passagem pelo nível intermediário apresenta-se então como a hora certa para que ambos reavaliem as idéias nas quais acreditam e nas quais baseiam seus comportamentos durante o aprendizado. Os professores devem estar conscientes do papel que desempenham, a saber, de que não se trata exatamente de aplicar novas técnicas de ensino da língua, mas de saber como provocar momentos de reflexão que levem seus alunos a assumirem conscientemente suas responsabilidades no aprendizado de uma língua estrangeira.
\end{abstract}

PALAVRAS-CHAVE: aprendizagem de línguas estrangeiras, crenças, autonomia

Baseando-nos em nossa experiência no ensino de língua inglesa para adultos, observamos que no processo de aquisição da língua estrangeira, o nível intermediário se apresenta como um desafio tanto para professores quanto para alunos. Ambos percebem que estão atravessando uma fase crítica. Neste nível, os alunos tendem a mostrar um grau elevado de ansiedade, reclamando de não sentir que estejam progredindo ou de progredir muito devagar. Alguns reagem a essa situação simplesmente desistindo; outros, sem saber o que fazer, procuram ajuda junto a seus professores. Os professores, em contrapartida, freqüentemente

\footnotetext{
${ }^{1}$ Regina Célia Halu é doutoranda em Letras na Universidade Federal do Paraná.

${ }^{2}$ Jeanne Marie Paraná é mestre em Letras e atualmente é atua no Centro de Línguas e Interculturalidade da Universidade Federal do Paraná.
} 
sentem-se responsáveis pela insatisfação e dificuldades de seus alunos, acreditando que deveriam ser capazes de apresentar soluções para todos.

Nem os alunos, nem os professores conseguem entender o que de fato está se passando. Para nós essa situação tão comum no nível intermediário apresenta-se como uma crise dentro do processo de ensino-aprendizagem. Essa crise é constantemente mencionada por autores de livros didáticos nas orientações que dão aos professores para uso de seus materiais. Por exemplo, LIZ e JOHN SOARS na introdução ao livro intermediário da série Headway (1986:iii) fazem a seguinte observação:

Headway foi escrito para atender as necessidades de alunos adultos, cujo principal objetivo é em geral ultrapassar o difícil platô do nível intermediário de inglês escolar e adquirir acuidade e um uso seguro da língua num nível intermediário avançado. (tradução nossa)

Na introdução do livro intermediário da série Blueprint, ABBS e FREEBAIRN (1995, p. 4) também comentam que os alunos de nível intermediário "freqüentemente sentem que seu progresso na aprendizagem alcançou um platô e que não estão indo para lugar nenhum. De repente, eles se dão conta do que vem pela frente e o quanto ainda há para aprender. Isso pode levar a uma sensação de frustração e desespero" (tradução nossa).

De certa forma, nós professores estamos cientes desse fenômeno e recebemos orientações genéricas sobre o que o aluno precisa para progredir no seu aprendizado. No entanto, em nenhum momento fica claro porque essa crise emerge.

$\mathrm{O}$ que procuramos fazer foi levantar os aspectos que caracterizariam essa crise e discuti-los levando em consideração tanto nossa experiência em sala de aula, incluindo as observações feitas por nossos alunos, quanto nosso conhecimento teórico sobre o processo de ensino-aprendizagem de línguas estrangeiras. Com isso pretendemos estabelecer uma ponte de compreensão entre o reconhecimento da crise e a escolha de atividades práticas de sala de aula que sejam adequadas para promover a continuidade do aprendizado.

Como dissemos anteriormente, acreditamos que o nível intermediário é um ponto crítico no processo de aprendizagem, isto é, ele pode ser pensado como um "rito de passagem" de um mundo onde a aprendizagem se dava de forma mais fácil, impulsionada pela motivação do novo e ancorada na orientação do professor, para outro no qual a aprendizagem só terá uma boa continuidade se o aluno se aprofundar numa reflexão sobre o que é aprender uma língua e atuar responsavelmente sobre o processo. É neste momento que os professores precisam ajudar seus alunos a se tornarem mais independentes. É preciso que 
os professores estejam cientes da importância do papel que desempenham, mas também dos limites de sua atuação.

\section{COMO A CRISE SE APRESENTA}

Ao discutir como a crise do nível intermediário se caracteriza, consideramos como professor e aluno se colocam frente a alguns aspectos dentro do processo de ensinoaprendizagem. Primeiramente, enfocamos a visão geral que o aluno tem do que seja aprender uma língua estrangeira. Em seguida discutimos a maneira como os alunos podem interpretar os conceitos teóricos mais difundidos e como isso pode afetar o aprendizado, utilizando como exemplo a teoria do período crítico. Finalmente, abordamos a questão da redefinição do papel do professor e do aluno nesse processo.

\section{O PROCESSO DE APRENDIZAGEM E SUAS METÁFORAS}

Sabe-se que o desempenho dos alunos depende das várias expectativas que eles nutrem e compartilham quanto ao seu aprendizado. No Brasil, estudos realizados com estudantes de Letras (BARCELOS, 1999) revelam que o aluno brasileiro tende a acreditar que a aprendizagem de uma língua pode se dar rapidamente, sem conflitos e sem esforço.

Essa visão de aprendizagem encontra-se especialmente reforçada quando o aluno está concluindo o nível básico. Até então aprender uma língua estrangeira era uma tarefa agradável motivada pela novidade, dirigida pelo professor e que conferia uma sensação de avanço rápido no aprendizado. Muitas vezes, ao completar o nível básico, o aluno acredita que já está munido de todas as ferramentas da língua - ele diz que sabe "se virar", ou seja, imagina que com o que adquiriu no nível básico o próximo passo é a fluência na língua, sem ter necessidade de refinar e/ou expandir o que aprendeu. Assim, o nível intermediário torna-se "chato" porque frustra mais essa expectativa, pois o aluno percebe que não consegue se expressar com fluência e sem cometer erros como desejava. A própria abordagem mais prevalente no ensino de línguas, a qual se propõe a trabalhar a partir de uma linguagem mais simples ou de estruturas e vocabulário mais básico, pode impedir que o aluno desenvolva uma percepção da complexidade do processo de aprendizagem. 
No nível básico, por exemplo, o aluno aprende regras simples e gerais sobre os tempos verbais da língua inglesa e o uso mais comum que eles têm. No nível intermediário, revisando seus conhecimentos, ele começa a contrastar o uso desses mesmos tempos e a se familiarizar com as suas exceções. Isto é, o nível intermediário se caracteriza principalmente por uma ampla revisão e um refinamento do que já se aprendeu no nível básico. Essa é, na verdade, a proposta que se encontra em materiais de ensino para nível intermediário. Por exemplo, no nível 3 da série New Interchange, RICHARDS, HULL e PROCTOR (1998) explicam que o trabalho a ser desenvolvido a partir daquele ponto se dará sobre a base construída nos níveis anteriores através de uma expansão dos aspectos gramatical, lexical e funcional.

Ao chegar ao nível intermediário, a reclamação do aluno de que ele não está aprendendo tão rapidamente quanto antes reflete uma realidade. Analisando a comparação que se faz da aprendizagem ao movimento de uma espiral crescente, percebe-se que os círculos da espiral, que corresponderiam ao processo de constante reciclagem e expansão do conhecimento da língua, são muito menores na base e aumentam gradativamente à medida que o processo se desenvolve. Ou seja, os ciclos de aprendizagem, reciclagem e expansão são mais curtos e se dão de forma muito mais rápida no nível básico. À medida que o aluno passa a acumular conhecimentos e competências, os mesmos ciclos tornam-se cada vez maiores e mais lentos. Como descrevem FINOCCHIARO e BRUMFIT (1983, p. 35), no modelo em espiral ou cíclico,

o mesmo tema sociocultural, categoria estrutural ou função de linguagem é estudado - sempre em sequiência lógica - em maior profundidade em sucessíveis níveis de aprendizagem. O material estudado anteriormente é resgatado, revisto e integrado com o novo aprendizado. (tradução nossa).

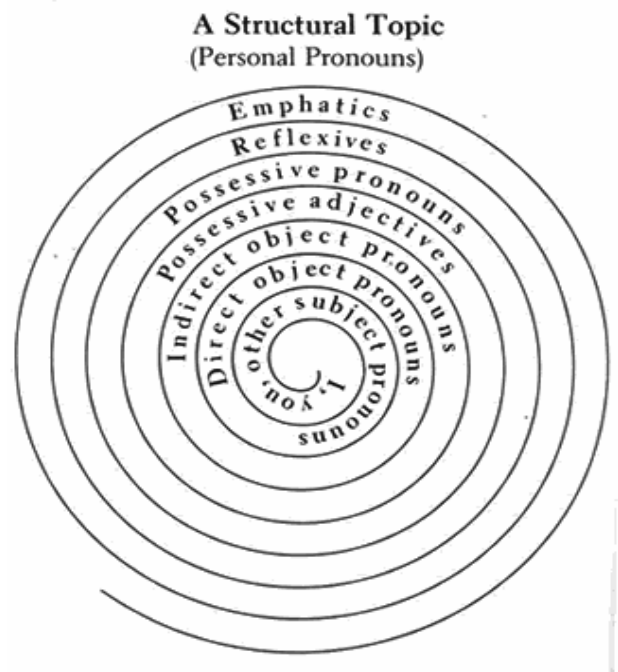

Figura 1 - exemplo da evolução em espiral de um tópico estrutural. (FINOCCHIARO e BRUMFIT, 1983, p. 36). 
Se fôssemos pensar numa comparação apropriada para demonstrar a expectativa do aluno quanto ao processo de aprendizagem, possivelmente veríamos não uma espiral crescente mas uma espiral em forma de tubo.
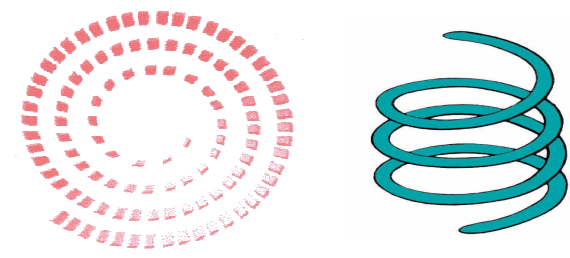

Figura 2 - Como a aprendizagem de uma L2/LE se desenvolve (espiral crescente) e como o aluno pode imaginar o mesmo processo (espiral-tubo).

Ou seja, se o aluno traz ainda consigo a expectativa de que a aprendizagem se dê sempre na mesma velocidade e com os mesmos resultados que alcançava no nível básico, ele vai ter seu desejo contrariado. De alguma forma, ao entrar no nível intermediário, ele é forçado a reavaliar essa expectativa, o que vem a causar um desconforto que começa a dar forma ao que chamamos de crise do nível intermediário.

\section{O PAPEL DOS CONCEITOS TEÓRICOS}

A frustração das expectativas em relação ao processo de aprendizagem é também reforçada pela maneira como alguns conceitos teóricos são popularizados. Entre eles destacase o exemplo da hipótese do período crítico, que foi muito divulgada na época de sua primeira formulação por volta de 1960. O problema nesse caso é que o aluno não foi colocado a par das reformulações da hipótese e ainda se atém à versão mais radical, na qual se acreditava que havia um limite de idade (até 10/12 anos) para que o aprendizado se desse de forma natural e sem esforço, depois do qual seria impossível ser completamente bem-sucedido (ELLIS, 1994, p. 484).

Hoje em dia sabe-se que essa hipótese sofreu várias críticas e que foi formulada uma versão mais branda. Esta versão propõe a existência de um limite de idade até o qual o aprendizado de línguas se daria mais naturalmente e com maior facilidade, mas admite que, dadas as condições adequadas, uma pessoa poderia atingir uma proficiência completa mesmo que iniciasse sua aprendizagem após aquele período ideal. Nessa versão não se fala sobre um período "crítico" e sim sobre um período "sensível" (sensitive period). Ainda assim, a 
hipótese continua sendo controversa, pois há dúvidas quanto à existência de diferenças significativas no aprendizado de uma segunda língua quanto ao fator idade. Como observa ELLIS (1994, p. 492), os resultados de estudos realizados apresentam explicações teóricas conflitantes.

A primeira versão teve um impacto bastante significativo tanto em alunos quanto professores. Principalmente os alunos adultos encontram naquela primeira hipótese uma justificativa para sua sensação de fracasso no aprendizado de uma língua. Muitas vezes, mesmo o professor não se encontra atualizado o suficiente para rebater essa argumentação, acreditando ele mesmo na sua validade.

Observamos que é no nível intermediário, ao se deparar com dificuldades no aprendizado, que o aluno começa a buscar explicações que justifiquem o seu aparente fracasso. Se até este ponto aconteceu de não se deparar com situações que questionassem sua capacidade de desempenho, agora há uma ansiedade que o impele a buscar respostas. Na busca dessas explicações, ele encontra alguns conceitos teóricos que foram mais difundidos, interpreta-os da sua maneira, podendo utilizá-los como uma desculpa para se acomodar no processo de aprendizagem, sem mudar sua atitude, ou até mesmo para desistir do aprendizado. É comum passar a ouvir dos alunos comentários como "estou muito velho pra aprender uma língua" ou "acho que não tenho aptidão pra línguas". Ou seja, exatamente no nível no qual o aluno mais precisa estar consciente de sua responsabilidade no processo, e adotar atitudes mais autônomas na condução de seu aprendizado, ele se arma desses pseudoconceitos teóricos esperando, engessado numa postura tradicional, que o professor continue assumindo o controle do aprendizado.

\section{O PAPEL DO ALUNO E DO PROFESSOR}

A necessidade imposta ao aluno no nível intermediário de uma mudança de visão de seu papel e do papel do professor gera conflitos e ansiedade. Em primeiro lugar, a pressão natural causada por qualquer tipo de mudança já cria uma situação de estresse. No caso do aprendizado de uma língua estrangeira, até a conclusão do nível básico, o aluno se encontra acostumado a procedimentos, técnicas e metodologias onde o professor se apresenta como um ponto de referência seguro e os passos a seguir estão relativamente estabelecidos. A mudança de uma posição na qual o aluno está confortável e seguro para outra onde lhe é exigida uma atitude mais atuante, responsável e crítica, não é vista com bons olhos. Na verdade, a 
tendência do aluno é não querer ver, mostrando uma resistência às possíveis propostas de mudança que o professor venha lhe trazer.

Em segundo lugar, soma-se a esse estresse próprio do ser humano frente a mudanças a interferência gerada pelo tipo de padrão histórico, cultural e político em que o aluno está inserido. No caso dos alunos brasileiros, já foi observado que eles mostram resistência a uma aprendizagem que exija maior autonomia de sua parte. Como resume BARCELOS (1999, p. 163), referindo-se à pesquisa realizada por CARMAGNANI ${ }^{3}$ :

Para [CARMAGNANI], o paternalismo, traço característico da sociedade brasileira, torna- se um grande empecilho para a tarefa de aprender a ser independente. A tradição é: o professor mostra e dirige caminhos e os alunos habituam-se a isso. Ainda segundo [CARMAGNANI], as representações que os brasileiros têm sobre aprendizagem refletem uma longa tradição centradas no professor, privilegiadas na escola primária e secundária, dificultando a experiência de aprendizagem auto-orientada num contexto mais amplo.

No nível intermediário, o que se espera do aluno, especialmente do adulto, é que passe a compartilhar responsabilidades e a construir uma nova visão sobre o que seja aprendizagem adquirindo cada vez mais autonomia. Nosso aluno não somente mostra uma resistência natural a essas mudanças, como também não se encontra culturalmente preparado para adotálas.

\section{VENCENDO A CRISE}

Mesmo um professor que tenha uma visão abrangente e atualizada das noções teóricas desenvolvidas sobre aprendizagem e que esteja ciente das mudanças de comportamento exigidas de alunos e professores a partir do nível intermediário, ainda assim ele pode não saber como agir para tentar superar as dificuldades típicas dessa fase. O desafio está em aprender a atuar sobre o sistema de crenças que cada aluno carrega consigo. Todo aluno tem uma visão do que seja aprender uma língua, um conjunto de explicações para justificar sucessos e fracassos, e uma visão dos papéis que professores e alunos devam desempenhar no processo. Esse sistema de crenças do aluno encontra-se num nível acima de sua habilidade de usar estratégias adequadas, seguir as rotinas de sala de aula ou de seu acesso a materiais e

\footnotetext{
${ }^{3}$ CARMagnani, A.M. Ensino Centrado no Aluno: a Adequação de uma Proposta Metodológica no Contexto Brasileiro. (Mimeo). 1993
} 
recursos didáticos. Estamos aqui nos referindo ao modelo desenvolvido por DILTS (1990), que estabelece cinco níveis de influências no nosso processo de pensamento.

No nível mais básico, encontra-se o ambiente de aprendizagem, ou seja, a sala de aula (por exemplo, recursos materiais, organização das carteiras, tamanho da sala). O nível seguinte compreende as ações executadas por professores e alunos, ou seja, as rotinas de ensino-aprendizagem. O terceiro nível diz respeito às habilidades, por exemplo, a capacidade que o aluno possui de usar determinado grupo de estratégias de aprendizagem. É no quarto nível que está organizado o seu sistema de crenças. No nível mais superior atua a identidade, a noção que o aluno tem de quem ele é.

Nesse sistema hierárquico, "quanto mais alto o nível lógico no qual operamos, mais influente ele se tornará sobre o resultado de um processo de pensamento ou de um ato de comunicação. Uma mudança num nível mais baixo, pode influenciar um nível mais alto, mas uma mudança num nível mais alto sempre terá algum efeito também em todos os níveis abaixo" (PUCHTA, 2000, p. 26). Isso significa, por exemplo, que mesmo que um aluno encontre-se na mais confortável sala de aula, com os recursos mais modernos, exposto a técnicas variadas de ensino, ainda assim ele não será bem sucedido se seu grau de motivação for baixo, se acreditar que não tem aptidão para línguas ou que passou da idade para aprendêlas.

Não basta o professor, ao identificar a crise, variar as técnicas de ensino, experimentar novas tecnologias, trabalhar com estratégias cognitivas, se não der ao aluno a oportunidade de refletir sobre seu aprendizado e abrir um caminho para mudanças em suas crenças e atitudes.

Como observaram LIGHTBOWN e SPADA (1999, p. 59), "praticamente todos os alunos, particularmente os mais velhos, possuem fortes crenças e opiniões a respeito de como a instrução de uma língua deve ser dada" e essas crenças "podem ser fortes fatores mediadores na sua experiência em sala de aula."

Portanto, a sugestão que fazemos aqui é de que dentro da crise do nível intermediário, ao procurar novas atividades, o professor inclua aquelas que trabalhem com o sistema de crenças de seus alunos. Esta é uma opção que já foi bastante pesquisada, resultando em material prático como as atividades de experimentação com estratégias metacognitivas apresentadas em Learning to learn English: a course in learner training (ELLIS; SINCLAIR, 1989) ou as propostas de GARDNER e MILLER (1996) para que o aluno desenvolva uma atitude mais independente. Atuando neste nível de influência sobre o processo de aprendizagem de forma a promover uma maior conscientização e independência por parte dos 
alunos, criam-se mais chances de transformar o nível intermediário em um período de valorização do progresso mais elaborado e exigente que o aluno experimenta.

\section{REFERÊNCIAS}

ABBS, B; FREEBAIRN, I. Blueprint Intermediate. Teacher's book. Longman, 1995.

BARCELOS, A.M.F. A Cultura de Aprender Línguas (Inglês) de Alunos no Curso de Letras. In: Almeida Filho, J.C.P., O Professor de Língua Estrangeira em Formação. Campinas, SP : Pontes, 1999. p.157-177

DILTS, R. Changing Belief Systems with NLP. Capitola, CA.: Meta Publications, 1990.

ELLIS, R. The Study of Second Language Acquisition. Oxford : OUP, 1994.

ELLIS, G.; SINCLAIR, B. Learning to learn English: a course in learner training. CUP, 1989.

FINOCCHIARO, M.; BRUMFIT, C. The functional-notional approach Oxford : Oxford University Press, 1983.

GARDNER, D.; MILLER, L. (eds.). Tasks for Independent Language Learning. TESOL, 1996.

RICHARDS, J.C.; HULL, J.; PROCTOR, S. New Interchange 3. Teacher's book. CUP, 1998.

SOARS, L.; SOARS, J. Headway Intermediate. Teacher's book. OUP, 1986.

PUCHTA, H. Beyond Materials, Techniques and Linguistic Analyses: the Role of Motivation, Beliefs and Identity. New Routes, 11, p. 26-29, 2000. 